\title{
EFFECT OF TRANSVERSE WELD FEED RATE ON MICROSTRUCTURE AND TENSILE PROPERTIES OF FSW WELD OF AA6061
}

\begin{tabular}{|l|l|}
\hline Ashwani Kumar & R S Jadoun \\
Assistant Professor & Professor \& Head \\
Mechanical Engineering Department & Industrial Production Engineering Department \\
SRMSCET, Bareilly & College of Technology, Pantnagar \\
UP, INDIA & G B Pant University of Agriculture \& Technology, \\
Email I.D: ashipe90@gmail.com & Pantnagar \\
& U S Nagar, Uttarakhand, INDIA \\
& Email I.D: rsjadoun@ gmail.com \\
\hline
\end{tabular}

\begin{abstract}
Friction stir welding (FSW) is a newly developed welding technology for welding of soft alloys. This is a solid state welding process in which the work material which is to be welded does not get melt and a joint can be easily obtained without the use of some additional filler material, gas protection or any other precaution. A hard rotating tool with a profile pin/probe and a shoulder gets inserted into the joint line and with the help of suitable transverse weld feed with some axially downward pressure the weld can be produced. Here the effect of three transverse weld feeds of FSW welding of AA6061 keeping rotational speed and axial pressure constant, were examined on the basis of weld microstructure and tensile properties. It was found that the microstructure of AA6061 is fine for low transverse weld feed as comparison to the other transverse feeds and on this transverse feed the tensile properties of the weld metal is higher than that of other two welding transverse feeds.
\end{abstract}

Keywords: Friction Stir Welding, Soft alloys, Solid state welding, Transverse weld feed, Microstructure, AA6061

\section{INTRODUCTION}

Friction Stir Welding (FSW) new technique of welding was invented in 1991 by Wayne Thomas of TWI (The Welding Institute) of United Kingdom. For the FSW (Friction Stir Welding) the jobs (metal sheets/metal plates) to be joined are aligned and clamped to each other and placed on a backing material. A non consumable cylindrical tool having a profile probe or pin rotates and plunged in to the joint line. The tool also does a transverse motion along the joining line, this produces the rubbing action and heat is generated which softens the job and the heated soft job material stirred by the probe and plastic flow of material takes place.

This is the solid state welding process in which the material does not reach at its melting point which reduces so many problems like segregation, severer residual stresses, distortion and evaporation of volatile elements. Fig. 1 shows the main process.

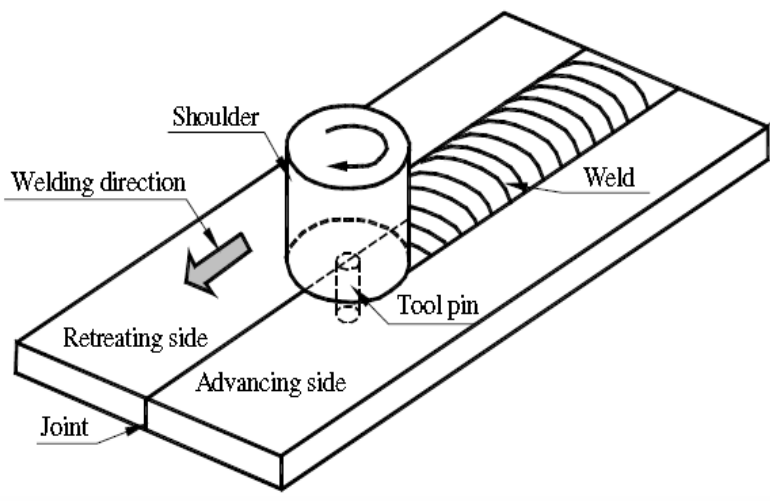

Fig. 1. FSW process

Originally, the FSW has been develop for joining high strength aluminum alloys and advanced aluminum alloys produced by power metallurgy. Friction Stir Welding in comparison to the automated gas metal arc welding improves the dimensional accuracy of the assembly and produces a $30 \%$ increase in joint strength [1].

Butt and Lap both types of joints can be weld through FSW. To produce the full penetration groove weld in a butt joint, the bottom of the tool must be close to the bottom of the work piece. In order to make a lap joint, the bottom of the tool must only extend through the bottom of the top sheet creating a metallic bond between two sheets. Due to the tool rotation, friction stir welds are not symmetric about weld centre line. Friction Stir welds are basically of two types hot welds, when lower ratio of welding speed to rotational speed and cold weld, when welding speed is higher [2].

FSW relies on localized forging of the weld region to produce the joint. In FSW heat is caused by rubbing of the tool faces against the work piece, and by viscoplastic dissipation of mechanical energy at high strain rates developed through interactions with the tool. During welding, the material along the joint is heated to a 


\section{ELK Asia Pacific Journals - Special Issue \\ ISBN: 978-81-930411-4-7}

softened condition transferred around the periphery of the tool and subsequently recoalesced along the back surface of the pin to produce weld. Minimization of distortion and residual stress is extremely important in welding of thick section material, such as in the ship building and heavy manufacturing industries [3].

Friction Stir Welding offers numerous benefits in the fabrication of aluminum products. With the use of Friction Stir Welding rapid and high quality welds of $2 \mathrm{xxx}$ and $7 \mathrm{xxx}$ aluminum alloys are possible, which were unweldable by the traditional fusion welding process. Heat generated is 80 to $90 \%$ of the melting points of the material to be welded. With FSW the traditional components, current and voltage are not present as the heat input is purely mechanical and thereby replaced by force, friction and rotation. Simply the heat generated in the Friction Stir Welding is given by the following simple relation:

\section{$\mathrm{Q}=\mu \omega \mathrm{FK}$}

Where, $\mathrm{Q}$ is the heat generated $\mu$ co-efficient of friction, $\omega$ tool rotational speed, $\mathrm{F}$ is the down force and $\mathrm{K}$ is the tool geometry constant. These all are also the parameters which should be controlled for the best welding [4].

FSW is hot shear joining process which involves complex interactions between verities of simultaneous thermo mechanical processes. The interactions affect the heating and cooling rates, plastic deformation and flow, dynamic recrystlization phenomena and the mechanical integrity of the joint. A unique feature of the FSW processes is that the transport of heat is aided by the plastic flow of the substrate close to the rotating tool [5].

With the help of FSW strong joints with low distortion, shrinkage and porosity can create. Butt welds, Overlap welds, T-sections and corner welds can be manufactured by the FSW [6]. Gravity does not affect FSW. It can be used in all positions as horizontal, vertical, overhead. In FSW circumferential, annular, non linear and three dimensional welds create no problems [7]. It also consumes less energy than that of fusion welding and no need of filler is required, which make it environmental friendly too [6].

\section{MATERIAL AND METHOD}

Aluminium alloys widely used in aerospace, automobile industries, railway vehicles, bridges and high speed ships, because it has light weight and higher strength to weight ratio, corrosion resistance and ductility. In all the discussed areas welding is the most used manufacturing process with a great challenge for designers and technologists.
Aluminium alloy AA6061 ( $\mathrm{Al}-\mathrm{Mg}-\mathrm{Si})$ is the most
widely used medium strength aluminium alloy, and has gathered wide acceptance in the fabrication of light weight structures [8].

The Extruded form of aluminium alloy AA6061 is used in the present investigation. It is heat treated up to $300^{\circ} \mathrm{C}$. Chemical compositions, physical properties and mechanical properties are given in Table I, Table II and Table III respectively.

TABLE I. Chemical composition of aluminium alloy AA6061

\begin{tabular}{|c|c|c|c|c|c|c|c|c|}
\hline IIg & $\mathrm{Si}$ & $\mathrm{Fe}$ & $\mathrm{Cu}$ & $\mathrm{Cr}$ & $\mathrm{VIn}$ & $\mathrm{Zn}$ & $\mathrm{Ti}$ & $\mathrm{Al}$ \\
\hline 0.63 & 0.42 & 0.42 & 0.12 & 0.19 & 0.05 & 0.08 & 0.02 & Bal. \\
\hline
\end{tabular}

TABLE II. Physical properties of aluminium alloy AA6061

\begin{tabular}{|c|c|c|c|}
\hline Density $\left(\mathrm{g} / \mathrm{cm}^{3}\right)$ & Melting Point( (C) & $\begin{array}{c}\text { Modulus of } \\
\text { Elasticity }(\mathrm{GPa})\end{array}$ & Poison Ratio \\
\hline 2.7 & 600 & 70.80 & 0.33 \\
\hline
\end{tabular}

TABLE III. Mechanical properties of aluminum alloy AA6061

\begin{tabular}{|c|c|c|c|c|}
\hline $\begin{array}{c}\text { Yield Strength } \\
(\mathrm{MPa})\end{array}$ & $\begin{array}{c}\text { 7limate Strength } \\
(\mathrm{MPa})\end{array}$ & $\begin{array}{c}\text { Elongation } \\
(\%)\end{array}$ & $\begin{array}{c}\text { Reduction in } \\
\text { cross sectional } \\
\text { area (\%) }\end{array}$ & $\begin{array}{c}\text { Hardness } \\
(\mathrm{HRB})\end{array}$ \\
\hline 280 & 310 & 16 & 11 & 65 \\
\hline
\end{tabular}

The principle alloying elements in AA6061 are Magnesium and Silicon. Magnesium is introduced in aluminium alloys to increase strength, and recrystalization temperature, allowing the alloy to maintain its strength at high temperatures. Manganese is usually added to aluminium to increase the amount of strain hardening during deformation. Iron is present in aluminium alloys as part of an intermetallic phase which provides a slide increase in its strength as well as better creep properties at moderately high temperatures. Magnesium is added to aluminium to improve its strength properties without sacrificing the alloy's ductility [9].

For FSW (Friction Stir Welding) square butt joint is prepared as shown in figure. The only difference here is of thickness of the work piece which is according to the fixture of the machine on which FSW was carried out. 
ELK

Asia Pacific Journals

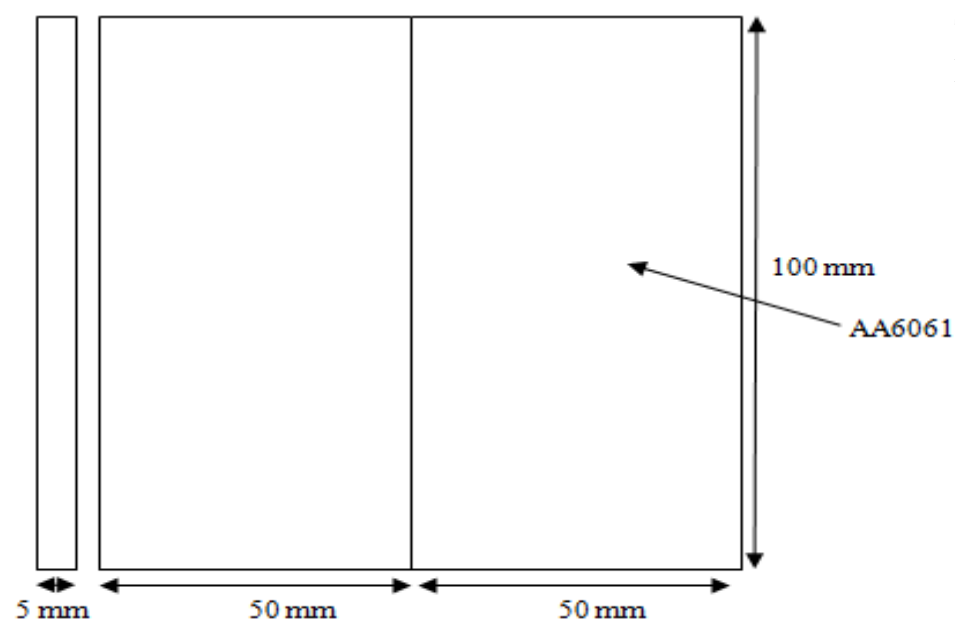

\section{ELK Asia Pacific Journals - Special Issue \\ ISBN: 978-81-930411-4-7}

The tool and the tool geometry are shown in the Fig. 4 and Fig. 5.

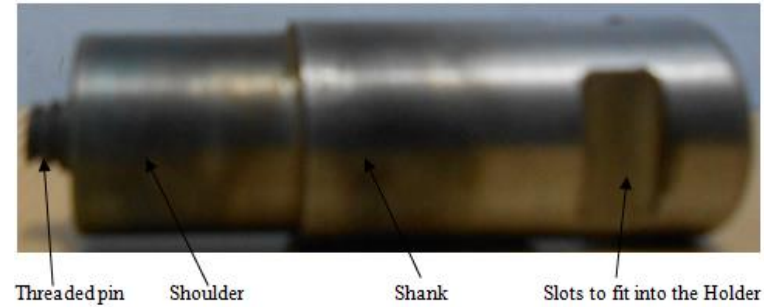

Fig. 4. FSW Tool

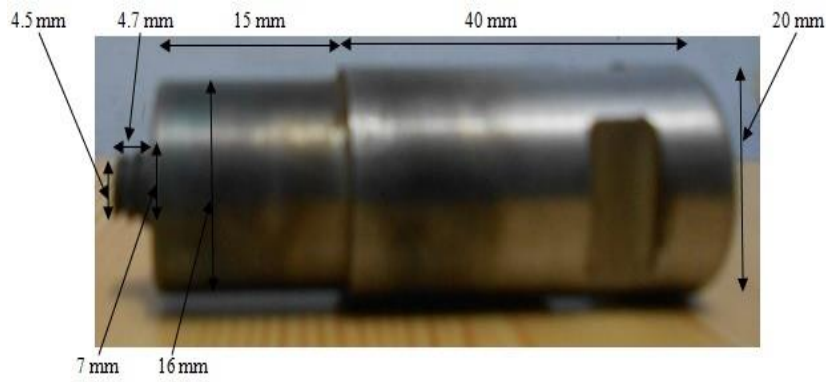

Fig. 5. Tool Geometry

The friction stir welding process is dominated by the effects associated with material flow and large mechanical deformation, which in turn is affected by process parameters such as rotational speed, welding speed and axial force [10].

Here three FSW joints were obtained at three different feeds keeping rotational speed of the tool and axial pressure constant. Zhang and Zhang (2009), examined the effects of welding parameters on the quality, temperature distribution and residual distortion in FSW parts, and determined that through careful process control, weld quality could be accurately predicted and controlled by sample size, fixture size and most importantly the rotation speed of the tool [11].

Subsize flat tensile specimens were prepared from the weld metal region (longitudinal direction) alone as per the IS standard to evaluate all weld metal tensile properties. The welded joints were sliced and then machined to the required shape for the tensile testing as shown in Fig. 6. 
ELK

Asia Pacific Journals

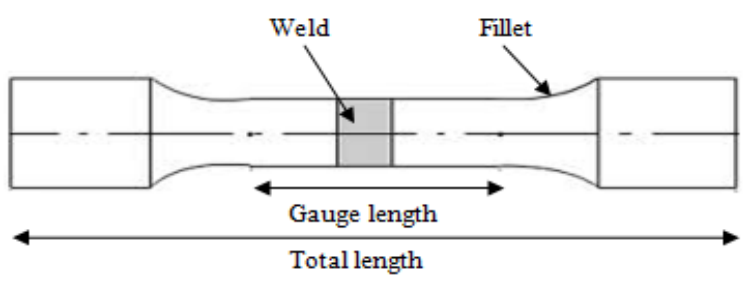

Fig. 6. Tensile test specimen

As per the IS standard Gauge length $\left(l_{\mathrm{g}}\right)$ will be given as follows,

$$
l_{\mathrm{g}}=4
$$

Where, $\mathrm{A}$ is the cross section area. IS guidelines were followed in preparing the test specimen. The tensile specimen is prepared to evaluate yield strength, tensile strength, elongation and reduction in cross sectional area.

Small size specimens are cut from the weld region for the SEM analysis. SEM analysis is used to get the microstructure of weld region. The following figure shows the SEM specimens, for three FSW joints.

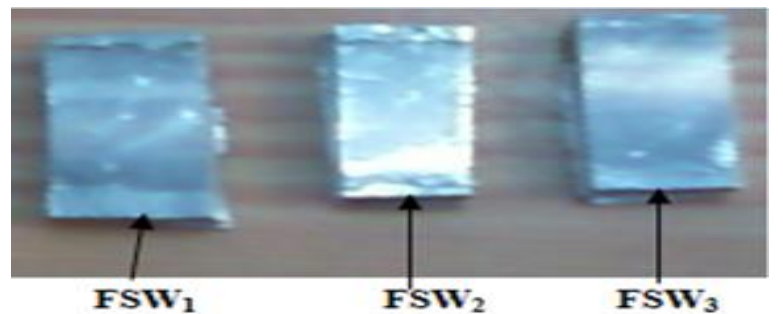

Fig. 7. Specimens for SEM analysis

\section{RESULTS AND DISCUSSIONS}

Here in this work microstructure and UTS of the weld joint is to be considered to get the best process

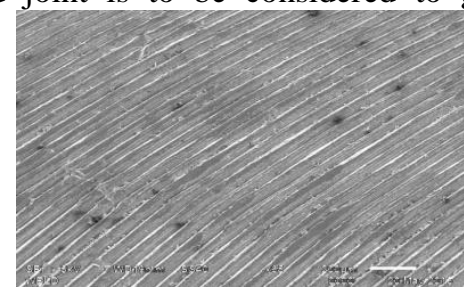

$\mathrm{FSW}_{1}$

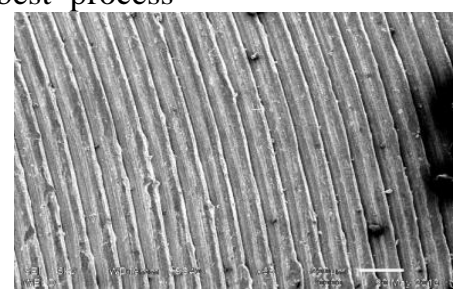

$\mathrm{FSW}_{2}$

\section{ELK Asia Pacific Journals - Special Issue \\ ISBN: 978-81-930411-4-7}

parameter for FSW of AA6061. The values of UTS for different parameters are shown in Table IV.

TABLE IV. UTS for different welding parameters

\begin{tabular}{|c|c|c|c|c|}
\hline Sr. N0. & $\begin{array}{c}\text { Rotation } \\
\text { speed (rpm) }\end{array}$ & $\begin{array}{c}\text { Feed/Welding } \\
\text { speed } \\
(\mathrm{mm} / \mathrm{min})\end{array}$ & $\begin{array}{c}\text { Axial } \\
\text { pressure } \\
(\mathrm{kN})\end{array}$ & UTS (MPa) \\
\hline $\mathrm{FSW}_{1}$ & 635 & 60 & 7 & 248 \\
\hline $\mathrm{FSW}_{2}$ & 635 & 75 & 7 & 236 \\
\hline $\mathrm{FSW}_{3}$ & 635 & 120 & 7 & 223 \\
\hline
\end{tabular}

Tensile properties of welded joints of $\mathrm{FSW}_{1}$, $\mathrm{FSW}_{2}$, and $\mathrm{FSW}_{3}$ shown in Table 4, clearly present that the $\mathrm{FSW}_{1}$ joint having the good tensile properties than that of $\mathrm{FSW}_{2}$, and $\mathrm{FSW}_{3}$ welded joints. At low transverse weld feed it is observed that the time for the stirring of the material is more as compare to the other two. This is the reason that the more effective stirring during the FSW welding makes the weld with more tensile properties.

During tensile testing it was observed that all the specimens were break down/failed at the weld region which means that the weld region possesses lower resistance to load than that the other regions, hence the joint properties is controlled by weld region chemical composition and microstructure [10].

In this study the microstructure of each and every joint has been examined at different locations of the joint. But it is found the joint mainly break/failed at the fusion zone, hence only the microstructure of the weld fusion zone is studied. The weld fusion zone microstructures of different welding processes are shown in the Fig.8.

Fig. 8. Microstructure of weld zone at $200 \mu \mathrm{m}$ scale 
tool transverse weld feed decreases at constant tool RPM and axial pressure. Here clearly can be seen that among $\mathrm{FSW}_{1}, \mathrm{FSW}_{2}$ and $\mathrm{FSW}_{3}$ the fine structure is

of

$\mathrm{FSW}_{1}$. different because different welding parameters. Degree of fineness of the onion rings increases as the

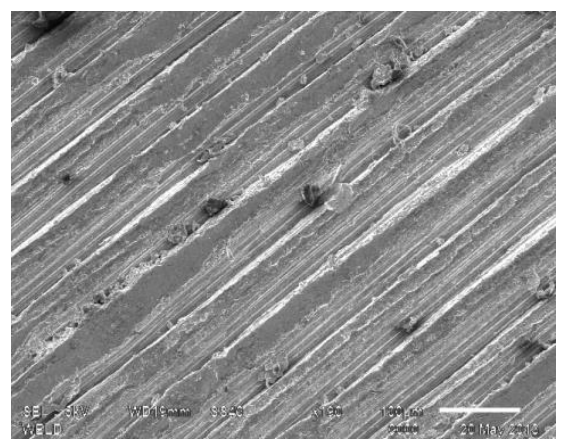

$\mathrm{FSW}_{1}$

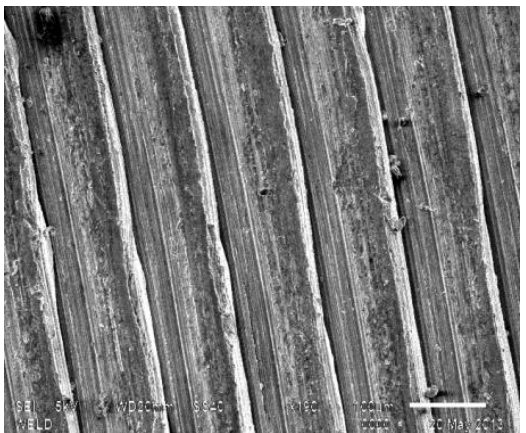

$\mathrm{FSW}_{2}$

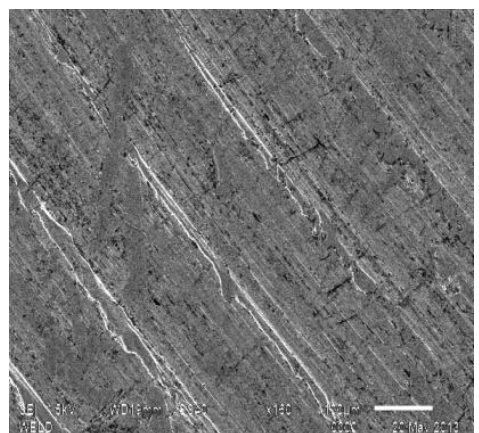

$\mathrm{FSW}_{3}$

Fig. 9. Microstructure of weld zone at $100 \mu \mathrm{m}$ scale

In case of $\mathrm{FSW}_{1}, \mathrm{FSW}_{2}$ and $\mathrm{FSW}_{3}$ the microstructure of $\mathrm{FSW}_{1}$ joint having grains distribution more uniform than the $\mathrm{FSW}_{2}$ and $\mathrm{FSW}_{3}$. Fine onion rings can be observed in $\mathrm{FSW}_{1}$ joint. $\mathrm{FSW}_{2}$ joint have more thick onion rings than $\mathrm{FSW}_{1}$. In $\mathrm{FSW}_{3}$ onion rings are approximately invisible because of high feed rate; here rings become coarse with some kind of dendritic grains.

In FSW it is also observed that the lower rotational speed produce more refined grain structure due to reduced thermal energy for grain recrystalization. Benavides et al. (1999), demonstrated that significant grain refinement could be achieved by pre-cooling the workpiece. This allowed temperature control while still utilizing a high degree of stirring action. Minimizing the energy for growth after recrystalization resulted in smaller grain size and an increase in strength, as predicted by the Hall-Petch equation,

$$
\sigma_{\mathrm{y}}=\sigma_{0}+
$$

Where, $\sigma_{\mathrm{y}}$ is the yield strength, $\sigma_{0}$ is the frictional strength, $\mathrm{k}$ is the strengthening coefficient and $\mathrm{d}_{\mathrm{avg}}$ is the average grain diameter [12].

\section{CONCLUSIONS}

FSW joints fabricated at three different transverse weld feeds keeping rotational speed and axial force constant. Here it is found that in this work the best suitable parameter for FSW welding of
AA6061 is, tool rotation speed as $635 \mathrm{rpm}$, tool transverse weld feed/ welding speed as $60 \mathrm{~mm} / \mathrm{min}$ and axial pressure as $7 \mathrm{kN}$, on low RPM milling machine FSW welding set up. Corresponding to this set of parameter we get the higher UTS i.e. $248 \mathrm{MPa}$ with fine grain weld microstructure with nice distribution of onion rings in the weld region.

\section{REFERENCES}

[1] Soundararanjan, V. Valant, R. Kovacevic, R. 2006. An Overview of R\&D work in Friction Stir Welding at SMU. Association of Metallurgical Engineers of Serbia. pp 275-295.

[2] Cederqvist, L. and Reynolds, A.P. 2001. Factors Affecting the Properties of Friction Stir Welded Aluminum Lap Joints. Gothenburg, Sweden. Proceedings of the $2^{\text {nd }}$ International Symposium on Friction Stir Welding.

[3] Lienert, T. J. Stellwag, W. L. Grimmett, B.B. Warke, R. W. 2003. Friction Stir Welding Studies on Mild Steel. Suplement to the welding Journal. The American Welding Society and the Welding Research Council. pp 1s-9s.

[4] ESAB. 2012. Technical handbook on FSW. ESAB Welding Automation.

[5] Nandan, R. DebRoy, T. Bhadeshia, H. K. D. H. 2008. Recent Advances in Friction Stir Welding - Process, Weldment Structure and Properties. Progress in Materials Science. Vol. 53. pp 9801023. 


\section{Asia Pacific Journals}

[6] The Welding Institute (TWI). 2009. Friction Stir Welding (FSW).

[7] Navy Metalworking Center (NMC), Concurrent Technologies Corporation (CTC). 2006. Friction Stir Welding, Strong, Ductile, and Environmentally Friendly. Contract No. N001406-D-0048 to the Office of Naval Research as part of the Navy ManTech Program.

[8] Balasubramanian, V. Ravisankar, V. Reddy, M. G. 2007. Effect of pulsed current welding on mechanical properties of high strength aluminium alloy. International Journal of Advanced Manufacturing Technolology (in press).
[9] Anthony, W. H. 1984. Aluminum: Properties and Physical Metallurgy. $4^{\text {th }}$ ed. American society for metals.

[10] Lakshminarayanan, A. K. Balasubramanian, V. Elangovan, K. 2009. Effect of welding processes on tensile properties of AA6061 aluminium alloy joints. International Journal of Advanced Manufacturing Technology. Vol. 40. pp 286296.

[11] Zhang, Z. and Zhang, H. W. 2009. Journal of Material Process Technology. Vol. 209 (1). pp 241-70.

[12] Benavides, S. Li, Y. Murr, L. E. 1999. Scripta Material., 1999. Vol. 41 (8). pp 809-848. 